\title{
ВMJ Global Health Modelling the pandemic: attuning models to their contexts
}

To cite: Rhodes T, Lancaster K, Lees S, et al. Modelling the pandemic: attuning models to their contexts. BMJ Global Health 2020;5:e002914. doi:10.1136/ bmjgh-2020-002914

Handling editor Seye Abimbola

Received 14 May 2020

Revised 5 June 2020

Accepted 8 June 2020
Check for updates

(C) Author(s) (or their employer(s)) 2020. Re-use permitted under CC BY-NC. No commercial re-use. See rights and permissions. Published by BMJ.

${ }^{1}$ Faculty of Public Health and Policy, London School of Hygiene and Tropical Medicine, London, UK

${ }^{2}$ Faculty of Arts and Social Sciences, University of New South Wales, Sydney, New South Wales, Australia

${ }^{3}$ Department of Global Health and Development, London School of Hygiene and Tropical Medicine, London, UK

Correspondence to Professor Tim Rhodes; tim.rhodes@lshtm.ac.uk

\section{ABSTRACT}

The evidence produced in mathematical models plays a key role in shaping policy decisions in pandemics. A key question is therefore how well pandemic models relate to their implementation contexts. Drawing on the cases of Ebola and influenza, we map how sociological and anthropological research contributes in the modelling of pandemics to consider lessons for COVID-19. We show how models detach from their implementation contexts through their connections with global narratives of pandemic response, and how sociological and anthropological research can help to locate models differently. This potentiates multiple models of pandemic response attuned to their emerging situations in an iterative and adaptive science. We propose a more open approach to the modelling of pandemics which envisages the model as an intervention of deliberation in situations of evolving uncertainty. This challenges the 'business-asusual' of evidence-based approaches in global health by accentuating all science, within and beyond pandemics, as 'emergent' and 'adaptive'.

\section{INTRODUCTION}

An editorial in the British Medical Journal on 'modelling the pandemic' pointed out that mathematical models have limits and uncertainties, especially when modelling novel infections, like COVID-19. ${ }^{1}$ Sridhar and Majumder also note that modelled projections are necessary for making policy decisions. Taking these two points together, they caution against an 'over-reliance' on models which can lead to 'missteps' and 'blind spots' in pandemic responses. As a solution to this complexity, they advocate for 'triangulation' across multiple data sources, and for 'humility', since no one discipline or approach 'has all the answers'.

A commentary in BMJ Global Health also focuses on the 'limits' of pandemic models. ${ }^{2}$ Richardson draws attention to how social and policy contexts shape how evidence is produced and put-to-use, arguing that models are 'merely fables' which reproduce prevailing narratives of global concern. Rather than treated simply as an evidence-based method of forecast or prediction, the model is here

\section{Summary box}

Mathematical models produce evidence to inform policy decisions in novel viral outbreaks and pandemics and in situations of uncertainty.

- Sociological and anthropological work shows how pandemic models do not always attune well in their local implementation contexts, and may also perpetuate harm through their silencing of alternative rationalities and models.

- There is an urgent need to better incorporate sociological and anthropological expertise in a triangulation approach to the modelling of pandemics.

- There is a need for an adaptive science approach which uses the model as an intervention of deliberation in an iterative response to emergent matters of concern.

configured as a form of 'biopower' in the extension of global health responses. ${ }^{3}$ Richardson argues that models reproduce dominant social and economic relations, and are in 'clear need of decolonising'. ${ }^{2}$ Whereas Sridhar and Majumder idealise a better evidenced model to progress towards a more 'definitive' knowledge, Richardson prompts us to reflect on the governing potentials of models as 'evidence-making interventions'. ${ }^{4}$

We take these two perspectives as points of departure for outlining the contributions potentiated by sociological and anthropological research in the modelling of pandemics. There is insufficient attention given to social contexts when modelling pandemics. This is the case in terms of how modelling evidence is produced and how it generates social and policy impacts in relation to matters of global and local concern. Attuning models to their implementation contexts is not just a question of scale and correspondence in terms of how models of pandemic translate locally, it is also a question of how different models are deliberated on and perform in evolving situations of uncertainty.

In this analysis, we draw on the cases of Ebola and influenza to consider lessons for the modelling of COVID-19 (See Summary 
box). Drawing on sociological and anthropological research, we trace how models can be investigated as matters of 'correspondence' and 'enactment' in relation to their social and policy contexts. ${ }^{56}$ While there is a tendency to concentrate on pandemic models as matters of 'evidence-based' concern, to 'better evidence' models towards greater precision and certainty, ${ }^{78}$ our analysis treats the model as an emergent 'evidence-making intervention' which not only reproduces but enacts pandemics in context. ${ }^{4}$ This helps to consider models as an element of adaptive evidence making, not only when intervening in pandemic emergencies but in the everyday, allowing for policy decision making that is responsive to evolving situations of complexity.

\section{MODELS IN PANDEMICS}

Mathematical models play a key role in decision making in pandemics. Projections of transmission, disease burden and infection control are essential elements of 'outbreak science ${ }^{910}$ and 'pandemic preparedness'. ${ }^{3} 7$ Variants of 'susceptible-infected-recovered' models are most common. ${ }^{8}$ More complex stochastic and dynamic simulation models also play a role. Modelled pandemics include HIV, ${ }^{11}$ hepatitis $\mathrm{C}^{12}$ severe acute respiratory syndrome (SARS),${ }^{10} \mathrm{H} 5 \mathrm{~N} 1$ (avian influenza), ${ }^{145} \mathrm{H} 1 \mathrm{~N} 1$ ('swine influenza'), ${ }^{16}$ Ebola $^{17-21}$ and currently, COVID$19 .^{22} 23$

Responding in pandemics not only demands the speeding-up of science, but requires evidence making that can adapt to evolving situations of complexity. ${ }^{24}$ In these situations, it is all the more apparent that evidence is uncertain, and that the outcomes of policy decisions and intervention are without guarantee. Global health emergencies therefore draw attention to the limits of 'evidence-based' intervention approaches. These idealise the translation of controlled interventions on the basis of seemingly unambiguous evidence verified through empirical observation and testing over time.${ }^{25}$ Outbreak science adapts to the emergency situation in a rapid assessment approach where evidence-making and decision-making emerge simultaneously, through triangulation, iteration and dialogue. ${ }^{9}$ In the presence of uncertainty, mathematical models offer a bridge to 'knowing' by generating scenarios to enable rapid policy decisions. ${ }^{8-10}$ As elements in global pandemic preparedness and response, models are deployed to imagine futures of unprecedented disease which cannot be known. ${ }^{7}$ Projections thus afford biosecurity through calculus, by anticipating unknowns, and 'dis-ease', into a governable present. ${ }^{526} 27$

A key mode of evidencing in scenario models is abstraction. One path in sociological and anthropological research is therefore tracing the inputs of models and how these relate to their contexts of production and implementation. The elements making-up a mathematical model-estimates, parameters, variables, assumptions, logics-are critical in shaping its outputs. In the face of empirical unknowns, inputs are abstracted from previous models as well as imputed in relation to theoretical plausibility. Models for policy thus blend various heterogeneous data (quantitative, qualitative, abstract, empirical) from various diverse contexts (different viruses, countries, localities, studies, historical periods) into a single calculative process to enable a decision. Models, as with any calculation machine, are performative ${ }^{528}$ Here then, the aim is to investigate how models have performative effects through the enumerations they create and how these detach from the origins of their production as they translate into new calculations and implementation contexts.

Treating models as performative draws attention to their governing potential as interventions in global health. ${ }^{29}$ It is therefore also important to explore how models 'have' and 'make' a context. This is a second, and more critically oriented, path for sociological and anthropological research. Models not only represent a pandemic, with more or less correspondence, but enact pandemic and its context. This is an important distinction because it illuminates how models can become detached from their implementation contexts while being attached to prevailing pandemic responses, in the process silencing alternatively situated models, with different logics and rationalities, for handling pandemics locally.

\section{Ebola}

In keeping with global pandemic response strategies, underwritten in WHO guidance, responses to Ebola outbreaks have been rooted in strategies of 'control at source' through 'containment'. ${ }^{30}$ Mathematical models have accentuated containment through isolation, quarantine and safe burial. ${ }^{17}{ }^{18}$ For instance, models projected the isolation of at least $70 \%$ of people with Ebola within 3 days of their becoming symptomatic as a critical threshold in reducing $\mathrm{R}_{0}$ to $1^{31}$ (the point at which the basic reproduction number, $\mathbf{R}_{0}$, indicates the force of transmission potential is neither increasing or decreasing). Yet, attempts to implement containment have revealed the basis of such assumptions as detached from local cultural logics and concerns. ${ }^{32}{ }^{33}$ Far from smooth, the implementation of containment efforts entangled as sites of miscommunication, mistrust, disrespect and symbolic violence, fuelling resistance in towns and villages. ${ }^{32-35}$ Efforts to separate caregivers from their dead and to conduct burials through cremation met with particular resistance. ${ }^{32} 36$ Household quarantine, and isolating people at risk to holding centres, inflicted profound social and economic harms in some places, including deaths linked to reduced access to food and medicines. $^{37}$

Pandemic models tend to assume an undifferentiated smooth implementation of containment interventions, making little or no incorporation of 'setting'. 71930 Yet, Ebola responses vary from place to place as an effect of how public authority in relation to care and burials emerge through negotiations locally. ${ }^{36}$ Few models have incorporated the transmission impacts of contacts with 
the deceased, ${ }^{20}$ a practice embedded in cultural logics of care and dignity. ${ }^{3738}$ Projections of transmission have overlooked local variation in the composition and dynamics of households. ${ }^{39}$ Case projections have been overestimated because community-based protective actions have been underestimated. ${ }^{36}$ Projections of containment based on hospital isolations, for example, led to large investments in upscaling hospital beds when these were not required by the time they were built given community responses. ${ }^{40}$ At the same time, global pandemic preparedness models emphasised investing in vaccines which only materialised at the tail end of epidemics, in some cases diverting investment from hospital care. ${ }^{41}$ Taken together, there is 'social science intelligence' ${ }^{42}$ that is 'rarely integrated into supremely important epidemiological projections', ${ }^{37}$ including because it is 'declared too difficult to model' ${ }^{37}$

Yet, attuning models to their contexts is not simply a matter of better incorporating local data capturing sociopolitical dynamics into the calculations of models. It also requires critically reflecting on how models perform as evidence-making interventions. ${ }^{4}$ Efforts to quantify elements of 'social context' into models, for instance, can enact an 'injustice' when reproducing overly simplified and fixed interpretations of 'context', 'culture', 'beliefs' and 'causality'. ${ }^{43}$ Agusto et al attempted to incorporate the effects of 'traditional beliefs' into modelled projections. ${ }^{44}$ Here, a composite parameter modifies transmission projections by accounting for beliefs that 'there is actually no such thing as Ebola', that 'Ebola is Government propaganda', that there is a 'fear of being quarantined', and that there is resistance to 'allowing their loved ones, who have died of Ebola, to be cremated'. The model alters the 'strength' of the composite measure of 'belief system' from 1.5 to 1.2 to 1 (unity) in low, moderate and high effectiveness scenarios of infection control in the 2014 Guinea outbreak to conclude that $R_{0}$ enters the range of 1.15-2.05 in the presence of 'detrimental traditional belief systems and customs'. ${ }^{44}$ A conclusion is 'educating the populace to abandon' such traditions. The model seeks to calculate, into a single measure, practices which are entangled in complex relations of trust, risk, respect, affect and care. A globalising narrative of 'blame' is reproduced through the calculation of transmission as a 'problem' of 'traditional beliefs' in need of correction, while simultaneously overlooking how local authorities might come together under the radar of official authorities (such as a paramount chief, staff from a Ministry of Health) to care for loved ones in creative and effective ways. ${ }^{36}$

We see then, how the political life and governing potential of models are afforded by their attachments in social relations. The material effects generated by US Centers for Disease Control (CDC) projections for the West Africa epidemic offer an example. In September 2014, the CDC estimated that 1.4 million people would die of Ebola in Liberia and Sierra Leone by January $2015 .{ }^{45}$ While the observed fatalities were much lower, at around 11310 , the projections served to mobilise over
US \$3.5 billion in humanitarian assistance, $150 \%$ more than the combined value of annual government budgets of the affected countries. ${ }^{46}$ The projections helped enact United Nations Security Council resolutions that declared the epidemics as threats to national peace and security, which in turn fostered a militarised approach to infection control, including through enforced containments and lockdowns. ${ }^{36}$ Ethnographic research has traced how local responses to Ebola in Sierra Leone adapted to the atmosphere of enforcement, revealing an alternative emergent 'people's science' in the Ebola response. ${ }^{36}$ Models materialise pandemic narratives, generating political effects which are navigated locally.

This reminds us that scientific calculus is never separate to, but a constitutive element in the making of, context. ${ }^{47}$ Richardson, for instance, has traced how epidemiological measures in the Ebola epidemic of the Democratic Republic of Congo (DRC) perpetuated structural inequalities by making absent their global power and colonial relations. ${ }^{43} 48$ The globalising narrative that people mistrusted and avoided internationally supported interventions because 'they did not believe that Ebola was real' is traced to epidemiological research published in the Lancet Infectious Diseases, ${ }^{49}$ which was then translated locally, including through media stories, among people with Ebola to reinforce the sense that transmission resulted from their 'false beliefs'. The circulating narrative of 'evidence-based' mistrust, with its particular causal logic of individual responsibility, silenced alternative narratives of the historical and political hinterland of DRC which materialised mistrust as a matter of postcolonial concern. We have then, different 'models' of emergent causation, with different cultural and epidemic logics, which a critical social science helps to notice. The implication is that models can be done differently, so that they attune as matters of becoming. In the case of DRC, for instance, models can adapt emergent causations of mistrust to incorporate measures of structural effect linked to global health, corporate and institutional actors and not only affected individuals. ${ }^{43}$ In an adaptive science approach, the model becomes a speculative intervention of "epistemic reconstitution, ${ }^{43}$; that is, an evidence-making event which generates an ontological change. ${ }^{4}$

\section{H5N1 influenza}

Influenza outbreaks further illustrate that mathematical models are not mere devices of correspondence in relation to contexts, be these local or global, but are modes of enactment which perform a pandemic in context. Anthropological studies of the mathematical models ${ }^{14}$ which shaped WHO responses to the H5N1 avian influenza outbreak, which emerged in Thailand in 2003, have noted various 'questionable assumptions' due to 'limited data' which led to massive overestimates of the antiviral pharmaceuticals needed for global stockpiling. ${ }^{30}$ The heterogeneous data inputs combined in these models included, for instance, age-specific attack rates 'from 
1957 data in Sheffield, UK' and 'incubation times from a study of infection on an aeroplane'. ${ }^{30}$ The models assumed that households were 'randomly distributed', thereby 'ignoring any social dynamics in rural village settings', and introduced 'no changes in behaviour as the pandemic accelerated', while also assuming that population and quarantine restrictions 'would work smoothly'. ${ }^{30}$ Although detached from local implementation contexts, the model was presented as 'valid' for 'Southeast Asia', with 'the potential to prevent millions of deaths'. ${ }^{14}$ The model attaches in a network of practices to enact a global narrative of pandemic threat of great magnitude, where the 'costs of failure' are projected as 'so catastrophic' that it is 'mperative to ensure that containment is given the best possible chance of success'. ${ }^{14}$

While the model parameter inputs were relative unknowns at the time, alternative models in Thailand produced very different case projections with much smaller estimates of antiviral pharmaceuticals needed for stockpiling. ${ }^{15}$ These alternative models, however, had less traction with global agencies coordinating the pandemic response. ${ }^{30}$ Focused instead on the local particularities of farming systems and trade markets, as well as differentiating risk in rural populations, these models emerged more slowly on the basis of empirical observations, generated different logics and assumptions, and produced more modest recommendations of lesser global policy impact. ${ }^{30}$ We have, as in the Ebola case above, different models being enacted, each located differently, and each projecting infection control in relation to their emergent situated matters of concern. Our point here is that models attach in their moments and contexts of production-be this in relation to global policy narratives, scientific method, causal logics or local concerns-and this materialises how their outputs translate (indeed, attach or detach) when implemented locally.

As it turned out, in the case of H5N1, there was to be no 'pandemic' as feared, and massive stockpiles of antiviral pharmaceuticals went largely unused. Yet, our point is that models enact pandemics even before their arrival is 'known'. Our example here draws on an ethnographic analysis of pandemic preparedness in Israel. ${ }^{50}$ Working with different pandemic outcomes projected by the higher (45000 deaths predicted) and lower (6000 deaths predicted) bounds of 1918 and 1957 past pandemics, the Ministry of Health of Israel ordered, in 2007, a policy of 'full preparedness' based on an intermediate 'attribution scenario' (assuming 30000 deaths).$^{50}$ Importantly, such modelled scenarios are 'treated as real', ${ }^{50}$ and become materialised in the present through policy and other actions. Projections actualise pandemics in the hereand-now, even if the pandemic event is yet-to-come. ${ }^{7}$ Pandemic models thus work as performative devices to 'make-up' pandemic possibility and context.

\section{H1N1 influenza}

Projections of H1N1 influenza outbreak in 2009 drew largely on 'prepandemic' models. ${ }^{1629}$ The models driving policy, for instance, in the UK, assumed a basic reproductive number, $\mathrm{R}_{0}$, in keeping with the influenza pandemic of 1918. These estimates, drawn from a time and society markedly different from the UK or Europe in 2009, were higher than those of the influenza pandemics of 1957 or 1968. Models elsewhere, for instance, in Australia, also based their key parameters on past outbreaks situated in different world contexts (in Australia's case, from past epidemics in the $\mathrm{USA}^{51}$ ). National and global projections shifted frequently, as well as dramatically, in the course of the outbreak, altering estimations of critical care need ${ }^{52}$ At the same time, modelled containment strategies (involving social distancing, isolation, quarantine and population movement restrictions) theorised an unhindered implementation, allowing no possibility for breakthrough infections or differentiated uptake. ${ }^{29}$ The modelled H1N1 pandemic is at once abstracted from local implementation contexts and made uncertain.

The uncertainty of the unfolding H1N1 pandemic reproduces the global policy response narrative of WHO, which theorises a threat of unknown massive potential, justifying a precautionary response. ${ }^{53} \mathrm{~A}$ "plausible uncertainty ${ }^{, 54}$ of a threat of 'disastrous proportions ${ }^{155}$ are key elements in the performance of pandemic preparedness. In the making of $\mathrm{H} 1 \mathrm{~N} 1$ pandemic, the WHO enacted the pathogen as an unpredictable danger ('The virus writes the rules on this one ${ }^{, 56}$; 'History has told us that these viruses are very, very, very unpredictable ${ }^{57}$ ). Crucially, the uncertainty of scientific projections performed the basis for global policies of precaution. As has been noted: 'The WHO's narration of risk in respect to the H1N1 pandemic accommodated scientific uncertainty by resting on an appeal to (rather than an erasure of) uncertainty as the basis of risk' ${ }^{53}$ Rather than present the science as if certain, WHO accentuated its contingency as a feature of the unknowability of pandemic threat. We see here, a pattern across viral outbreaks-from Ebola to influenza-where the pandemic model performs a qualitative scenario of generalised threat rather than predicts with local precision. ${ }^{7}$ In the end, the projections driving H1N1 pandemic preparedness, which accentuated the urgent need for the stockpiling of (partially effective) antiviral pharmaceuticals, overestimated the 'pandemic' and its harms, even to the extent that the WHO was accused of 'faking' these to boost industry profits. ${ }^{58}$ Models, as with any evidence-making intervention, are calculative machines of invention; a means to know and to act in uncertainty.

\section{COVID-19}

As with Ebola and influenza, models of COVID-19 reproduce pandemic preparedness narratives of "control at source' through 'containment'. They also draw on past pandemic models, of different viruses, in different contexts, to enact a COVID-19 pandemic in-the-now. There are shared input traces, for instance, in the assumptions driving simulations of SARS coronavirus 2 (SARS-CoV-2) today and influenza dating back to $1918 .^{22}$ 
Even the most basic yet highly consequential parameters shaping COVID-19 projections are emergent, including estimates of infectivity, transmissibility, asymptomatic infection and incubation time, with models adapting in relation to heterogeneous data triangulated from multiple sources and contexts. An enquiry on models informing policies of COVID-19 infection control in the UK, for instance, emphasised how assumptions drawn from past pandemic models of influenza have led to underestimates of cases and deaths linked to hospitals and care homes, given how influenza virus is differentially transmitted to SARS-Cov-2, with different clinical effects, in relation to age and in response to infection controls in different settings such as schools, hospitals and care homes. ${ }^{59}$ Estimates of $\mathrm{R}_{0}$ in relation to SARS-CoV-2 have not only shifted from original assumptions based on those of influenza and SARS, but evolve as empirical data emerges (with earlier models underestimating $\mathrm{R}_{0}$ ), and crucially, are heterogeneous and multiple on account of their contexts of production. ${ }^{60}$ In the UK, for instance, estimated $\mathrm{R}_{0}$ in care homes is quite different to that estimated in community or other settings, and yet this singular calculation is mobilised in policy, as well as captured in the popular imagination, as a population-wide metric of modelled infection control. The pandemic model, as we have seen above, performs a generalised threat of unknown yet great potential to enact a precautionary response, and models of COVID-19 are no exception. Such models are not without controversy. ${ }^{61}$ They are recognised, including by modellers, to have generated 'very alarmist values' as a 'worst case scenario' because this is 'what policy-makers needed at that time'. ${ }^{59}$

Unlike previous pandemics, the performativity of COVID-19 models is expanded by the intensity and scale of public and media engagement with projections and metrics. ${ }^{62}$ Controversy linked to shifting national policies based on emergent modelled scenarios of 'herd immunity' (viral mitigation) and 'lockdown' (viral suppression) have enacted the mathematical model, its adaptations, and the logics and science of these, as sites of public trouble. ${ }^{61}$ There is ongoing public deliberation in some settings about trusting generalised projections made in the absence of empirical data, especially that derived from community testing initiatives. ${ }^{61}$ Sociological studies have sought to 'follow the numbers' of COVID-19 models as they travel in policy and public communication to investigate how projections 'go public' as sites of social concern. ${ }^{61}$ Here, the model is not treated as if separate from society, as if facts can be isolated from concerns, but is understood as made-to-matter in the local of the everyday. The 'domestication' of the mathematical model and citizen engagement in modelling science precipitated by COVID-19 potentiates the model as a site of deliberative intervention in evidence-making incorporating multiple forms of expertise. ${ }^{6263}$

COVID-19 also indicates the urgent need to model 'beyond the virus'. Far beyond attenuating for differentiations between multiple forms of virus (ie, moving beyond the prepandemic influenza model), the pandemic model requires local differentiation and adaptation the moment it is released. Applied as a tool for navigating emergency and novel situations, the pandemic model is always a matter of becoming, as it transforms into multiple, dynamic and iterative versions of localised adaptation. While acknowledging that "no public health intervention with such disruptive effects on society has been previously attempted', ${ }^{22}$ pandemic models tend to simplify. Social distancing is obviously not a single dose or one-off "intervention' but a complex of practices, made-up of multiple combination effects (closures, population mixing, isolation, quarantine) in particular settings (urban, rural, household, community, hospitals, care homes) at particular times (immediate, short and longer term, in cycles of viral peaks, troughs and rebound). The 'social distancing complex' is in urgent need of ethnographic unpacking. Pandemic models tend to assume smooth intervention translations as rational cost-benefit actions, ${ }^{14} 1629$ yet risk and intervention engagements emerge as matters of negotiation, structuration and habit. While COVID-19 models tend to assume relatively undifferentiated publics engaging in a smooth roll-out of viral mitigation or suppression, empirical evidence suggests that different social distancing measures affect populations differently, including their capacity to isolate or shield, and shaped by social and material inequalities. ${ }^{64}$ The intensity and sustainability of community engagements in infection control are highly variable in population, time and space, and differ from influenza-informed assumptions. ${ }^{59} 64$ COVID-19 pandemic models have yet to treat SARS-CoV-2 and its control as a matter of dynamic adaptation located in complex evolving systems. ${ }^{65}$ The time to better attune COVID-19 models to their local contexts is now.

\section{MODELLING AS AN ADAPTIVE SCIENCE}

A core challenge in novel viral outbreaks and emergencies is how to act in an evolving situation of complexity and need. Emergency situations make it all the more apparent that evidence is uncertain, and that outcomes are without guarantee. ${ }^{24}$ This troubles the 'business-asusual' of evidence-based intervention which assumes an ideal of 'definitive information' through empirical verification. ${ }^{14}$ 'Evidence-based' approaches imagine that interventions, once tested and verified, will translate into new contexts and with similar effects. ${ }^{25}$ Pandemics are evolving situations of complexity which challenge assumptions that evidence can be held apart from the contexts in which it is made and put-to-use, making more obvious the situated nature of intervention outcomes, and the need for adaptive modes of evidencing and intervening. ${ }^{24}$

The approach in emergency situations is usually for 'evidence-based' interventions to recalibrate what constitutes 'evidence-enough' to enable decision making. ${ }^{24}$ Strategies of pandemic preparedness do this by accepting a situation of unknowns to deploy precautionary 


\section{Mathematical modelling in an adaptive science approach}

- Trace the inputs of models to their original contexts of production to investigate how models reassemble their inputs to perform new calculations in new contexts.

- Attune the inputs of models to their contexts of implementation through ethnographic and social research and through local expertise.

- Follow the outputs of models to map how they transform, are putto-use, and made-to-matter, in new contexts.

- Trace the social and material effects, including unforeseen, of models as they travel in policy and public life.

- Map how the assembly and use of models reproduces as well as performs particular narratives of governance in relation to health, disease and populations.

- In all stages of modelling, from production to implementation, use the model as an intervention for deliberation and dialogue with multiple stakeholders in order to shape models iteratively in response to emerging concerns in an adaptive approach.

- Use models speculatively to explore emerging logics of causality in response to local matters of concern.

actions. ${ }^{7}$ In viral outbreaks, it is said that 'hesitation is more dangerous than trying out potentially ineffective methods', and that pandemic responses need to 'adapt and learn from mistakes'. ${ }^{31}$ Accordingly, it is argued that it is not 'until the outbreak is over' that it becomes known whether 'we have launched the best response'. ${ }^{31}$ Pandemic situations, therefore, 'highlight the need to think differently about evidence making and decision making, acknowledging that unambiguous evidence in evolving situations of complexity is an unachievable ideal, and that the effectiveness of response measures is situated and emergent'. ${ }^{24}$

Models, therefore, occupy an unusual space in evidence-based intervention. They mobilise multiple forms of evidence, from diverse sites and settings, in order to bridge between relative knowns and unknowns to evidence-make possible futures. In an evidence-based approach, models are thought to become better attuned to their implementation contexts as empirical data emerge. The assumption here is that the 'accuracy' and 'predictability' of models becomes verified through their iterative evidencing as measures which correspond to a context. Models then, are experimental, as they generate scenarios and propositions, including policy proposals, for deliberation as well as testing. ${ }^{10}$ While pandemic models tend to be a priori theory driven and scenario based, in an evidence-based adaptive approach, models also purport to offer generative, dynamic and emergent evidence, become less 'pandemic' as they are localised, and become less speculative as they offer empirically informed explanation and evaluation. The pandemic model is necessarily momentary, as it shifts from enacting a rationality of anticipatory governance for all and everywhere (this is what the narrative of pandemic affords) towards intervening locally on the basis of empiricallybased risk predictions presumed to map known infections in actual populations. ${ }^{7}$

Yet adaptive science, as we see it, does not assume a linear iterative progression towards an ever more 'accurate' or 'valid' correspondence with a pre-existing reality or context. Rather than promising to converge on a 'single point' of evidence through iteration, models in adaptive science can be treated as forms of deliberation to deepen understandings of interventions as contingent local concerns rather than as fixed globalised facts. ${ }^{66}$ Viewed in this way, models enhance the capacity of knowledge to translate across boundaries, such as when science translates into policy and when global strategies are tweaked into local actions. ${ }^{67}$ The model, precisely because it has latitude as a space of triangulation and speculation, potentiates a working relationship, in which dialogue is made possible. ${ }^{6168} \mathrm{~A}$ more open approach to triangulation reveals the multiple situated versions, indeed 'models', of pandemics-in-context which are at play, and made-to-matter, in any given moment.

Our analysis has shown how global narratives of pandemic preparedness generate a context in which models work as tools of anticipatory governance, which need not correspond or attune well locally. Indeed, they may end up perpetuating harm through their silencing of alternative cultural logics and models. Pandemic models are always made multiple-for there are multiple competing models, iterations of adapting models, as well as multiple materialisations of models in any given context, all with different effects. This is why we see potential, through engagement with critical social science approaches, in attuning the model as an adaptive intervention in relation to emergent local matters-of-concern (See box 'mathematical modelling in an adaptive science approach'). In our interpretation, 'attunement' implies a coconstitutive recursive entanglement between models and contexts as they emerge, and merge, relationally. In attuning models to-and with-their contexts in an adaptive science approach, neither models nor contexts are taken as momentarily stable while one is adapted in relation to the other, for both are always emergent and entangled.

\section{CONCLUSION}

The adaptive science we imagine does not idealise or hold on to a certainty of information becoming 'definitive'. The challenge is not simply to 'speed-up' evidence-based approaches, but rather to enact evidence in a different mode, in ways that are responsive to an emergent and evolving situation. Whereas evidence-based approaches presume certainty as a possibility through iterative progression, though not necessarily in the time of the pandemics to which they respond, an adaptive evidencemaking approach accepts contingency as a fundamental element of all forms of science and intervention. ${ }^{4}$ In our view, neither models nor science can put an end to 
uncertainty or make ultimate discovery; evidence is always without guarantee. But adaptive science offers materials for living-with uncertainty. While pandemics bring to attention the unknown, an adaptive science is not only the preserve of the novel or the urgent but is also applicable to the science of the mundane and everyday. We therefore envisage adaptive science as the 'new normal' in a world of emergent contingencies, and encourage a shift from the 'business-as-usual' ideal of evidence-based approaches. It is time to embrace an adaptive science to better attune COVID-19 models to their implementation contexts.

Twitter Tim Rhodes @tim_rhodes

Contributors TR led the writing for this analysis with all coauthors contributing throughout.

Funding The authors have not declared a specific grant for this research from any funding agency in the public, commercial or not-for-profit sectors.

Competing interests None declared.

Patient consent for publication Not required.

Provenance and peer review Not commissioned; externally peer reviewed.

Data availability statement There are no data available for sharing linked to this analysis which is based on literature in the public domain.

Open access This is an open access article distributed in accordance with the Creative Commons Attribution Non Commercial (CC BY-NC 4.0) license, which permits others to distribute, remix, adapt, build upon this work non-commercially, and license their derivative works on different terms, provided the original work is properly cited, appropriate credit is given, any changes made indicated, and the use is non-commercial. See: http://creativecommons.org/licenses/by-nc/4.0/.

\section{ORCID iDs}

Tim Rhodes http://orcid.org/0000-0003-2400-9838

Kari Lancaster http://orcid.org/0000-0002-2411-7970

Shelley Lees http://orcid.org/0000-0003-0062-7930

Melissa Parker http://orcid.org/0000-0003-0829-2741

\section{REFERENCES}

1 Sridhar D, Majumder MS. Modelling the pandemic. BMJ 2020;369:m1567.

2 Richardson ET. Pandemicity, COVID-19 and the limits of public health 'science'. BMJ Glob Health 2020;5:e002571.

3 David P-M, Le Dévédec N. Preparedness for the next epidemic: health and political issues of an emerging paradigm. Crit Public Health 2019;29:363-9.

4 Rhodes T, Lancaster K. Evidence-making interventions in health: a conceptual framing. Soc Sci Med 2019;238:112488.

5 Rhodes T, Lancaster K. How to think with models and targets: hepatitis $\mathrm{C}$ elimination as a numbering performance. Int J Drug Policy 2020:102694.

6 Myers N. Rendering life molecular: models, Modelers and excitable matter. London: Duke University Press, 2015.

7 Lakoff A. Unprepared: global health in a time of emergency. University of California Press, 2017.

8 Kucharski A. Rules of contagion: why things spread and why they don't. London: Profile Books, 2020.

9 Rivers C, Chretien J-P, Riley S, et al. Using "outbreak science" to strengthen the use of models during epidemics. Nat Commun 2019;10.

10 Glasser JW, Hupert N, McCauley MM, et al. Modeling and public health emergency responses: lessons from SARS. Epidemics 2011;3:32-7.

11 Hallett TB, Menzies NA, Revill P, et al. Using modeling to inform international guidelines for antiretroviral treatment. AIDS 2014;28(Suppl 1):S1-4.

12 Martin NK, Vickerman P, Hickman M. Mathematical modelling of hepatitis $\mathrm{C}$ treatment for injecting drug users. J Theor Biol 2011;274:58-66.
13 Lipsitch M, Cohen T, Cooper B, et al. Transmission dynamics and control of severe acute respiratory syndrome. Science 2003;300:1966-70.

14 Ferguson NM, Cummings DAT, Cauchemez S, et al. Strategies for containing an emerging influenza pandemic in Southeast Asia. Nature 2005;437:209-14.

15 Gilbert M, Xiao X, Pfeiffer DU, et al. Mapping H5N1 highly pathogenic avian influenza risk in Southeast Asia. Proc Natl Acad Sci U S A 2008;105:4769-74.

16 Ferguson NM, Cummings DAT, Fraser C, et al. Strategies for mitigating an influenza pandemic. Nature 2006;442:448-52.

17 Chretien J-P, Riley S, George DB. Mathematical modeling of the West Africa Ebola epidemic. Elife 2015;4:e09186.

18 Dénes A, Gumel AB. Modeling the impact of quarantine during an outbreak of Ebola virus disease. Infect Dis Model 2019;4:12-27.

19 Chowell G, Hengartner NW, Castillo-Chavez C, et al. The basic reproductive number of Ebola and the effects of public health measures. J Theor Bio 2014;229:119-26.

20 Legrand J, Grais RF, Boelle PY, et al. Understanding the dynamics of Ebola epidemics. Epidemiol Infect 2007;135:610-21.

21 Rivers CM, Lofgren ET, Marathe M, et al. Modelling the impact of interventions on an epidemic of Ebola in Sierra Leone and Liberia. PLoS Curr 2014;6.

22 Eubank S, Eckstrand I, Lewis B, et al. Commentary on Ferguson, et al., "Impact of Non-pharmaceutical Interventions (NPIs) to Reduce COVID-19 Mortality and Healthcare Demand". Bull Math Biol 2020;82:52.

23 Hellewell J, Abbott S, Gimma A, et al. Feasibility of controlling COVID-19 outbreaks by isolation of cases and contacts. Lancet Glob Health 2020;8:e488-96.

24 Lancaster K, Rhodes T, Rosengarten M. Making evidence and policy in public health emergencies: lessons from COVID-19 for adaptive evidence-making and intervention. Evid Policy 2020.

25 Sackett DL, Straus SE, Richardson WS, et al. Evidence-based medicine. 2nd edn. Edinburgh: Churchill Livingston, 2000.

26 Michael M. Futures of the present: from performativity to prehension In: Brown N, Rappert B, Webster A, eds. Contested futures: a sociology of prospective Techno-science. Aldershot: Ashgate Publishing, 2020: 21-42.

27 Adams V, ed. Metrics: What Counts in Global Health. Durham, NC: Duke University Press, 2016.

28 Callon M, Numiesa F. Economic markets as calculative and calculated collective devices. Organiz Stud 2005;26:1229-50.

29 Mansnerus E. Using model-based evidence in the governance of pandemics. Sociol Health IIIn 2013;35:280-91.

30 Leach M, Scoones I. The social and political lives of zoonotic disease models. Social Sci Med 2013;88:10-17.

31 Whitty CJM, Farrar J, Ferguson N, et al. Tough choices to reduce Ebola transmission. Nature 2014:515:192-4.

32 Coltart CEM, Lindsey B, Ghinai I, et al. The Ebola outbreak, 2013-2016: old lessons for new epidemics. Philos Trans $R$ Soc Lond B Biol Sci 2017;372:72:20160297.

33 Thiam S, Delamou A, Camara S, et al. Challenges in controlling the Ebola outbreak in two prefectures in guinea: why did communities continue to resist? Pan Afr Med J 2015;22(Suppl 1):22.

34 Wilkinson A, Parker M, Martineau F, et al. Engaging 'communities': anthropological insights from the West African Ebola epidemic. Philos Trans R Soc Lond B Biol Sci 2017;372:20160305.

35 Richardson ET, Kelly JD, Sesay O, et al. The symbolic violence of 'outbreak': A mixed methods, quasi-experimental impact evaluation of social protection on Ebola survivor wellbeing. Soc Sci Med 2017:195:77-82.

36 Parker M, Hanson TM, Vandi A, et al. Ebola and public authority: saving Loved ones in Sierra Leone. Med Anthropol 2019;38:440-54.

37 Abramowitz S. Epidemics (especially Ebola). Annu Rev Anthropol 2017;46:421-45.

38 Hewlett BS, Hewlett BL. Ebola, culture and politics: the anthropology of an emerging disease. Belmont, CA: Wadsmowth Cengage, 2008.

39 Kiskowski M, Chowell G. Modeling household and community transmission of Ebola virus disease: epidemic growth, spatial dynamics and insights for epidemic control. Virulence 2016;7:163-73.

40 Kirsch TD, Moseson H, Massaquoi M, et al. Impact of interventions and the incidence of Ebola virus disease in Liberia-implications for future epidemics. Health Policy Plan 2017;32:205-14.

41 Nguyen VK. Ebola: how are we became unprepared, and what might come next, cultural anthropology online. , 2017: 2014, 30.

42 Abramowitz SA, Bardosh KL, Leach M, et al. Social science intelligence in the global Ebola response. Lancet 2015;385:330.

43 Richardson ET, McGinnis T, Frankfurter R. Ebola and the narrative of mistrust. BMJ Glob Health 2019;4:e001932. 
44 Agusto FB, Teboh-Ewungkem MI, Gumel AB. Mathematical assessment of the effect of traditional beliefs and customs on the transmission dynamics of the 2014 Ebola outbreaks. BMC Med 2015;13:96.

45 Meltzer MI, Atkins CY, Santibanez S, et al. Estimating the future number of cases in the Ebola epidemic--Liberia and Sierra Leone, 2014-2015. MMWR Supp/ 2014;63:1-14.

46 Dubois M, Wake C. The Ebola response in West Africa: exposing the politics and culture of international aid. humanitarian group working paper. London: Overseas Development Institute, 2015.

47 Latour B. Science in action: how to follow scientists and engineers through Society. New Jersey: Harvard University Press, 1987.

48 Richardson E. On the coloniality of global public health. Med Anthro Theory 2019.

49 Vinck P, Pham PN, Bindu KK, et al. Institutional trust and misinformation in the response to the 2018-19 Ebola outbreak in North Kivu, DR Congo: a population-based survey. Lancet Infect Dis 2019;19:529-36.

50 Saminmian-Darash L. Governing future potential biothreats: toward an anthropology of uncertainty. Curr Anthro 2013;54:1-22.

51 Baker PRA, Sun J, Morris J, et al. Epidemiologic modeling with FluSurge for pandemic (H1N1) 2009 outbreak, Queensland, Australia. Emerg Infect Dis 2011;17:1608-14.

52 Ercole A, Taylor BL, Rhodes A, et al. Modelling the impact of an influenza $\mathrm{A} / \mathrm{H} 1 \mathrm{~N} 1$ pandemic on critical care demand from early pathogenicity data: the case for sentinel reporting. Anaesthesia 2009;64:937-41.

53 Abeysinghe S. An uncertain risk: the world Health organization's account of H1N1. Sci Context 2014;27:511-29.

54 Williams SN. 'Plausible uncertainty': The negotiated indeterminacy of pandemic influenza in the UK. Crit Public Health 2008;18:77-85.

55 Walker D, Davis M, Stephenson N. Australia's pandemic influenza 'Protect' phase: Emerging out of the fog of pandemic. Crit Public Health 2016;26:99-113.

56 Chan M. WHO press Briefing, June 11. World Health Organization, 2009.
57 Ryan M. Who press Briefing, May 2. World Health Organization, 2009.

58 Chan M. WHO Director-General replies to the BMJ. BMJ 2010;340:c3463.

59 UK Parliament House of Lords Science and Technology Committee. Inquiry into the science of COVID-19: the role of modelling, 2020. Available: https://www.parliament.uk/business/committees/ committees-a-z/lords-select/science-and-technology-committee/ news-parliament-2019/covid-19-epidemiological-models/

60 Hilton J, Keeling M. Estimation of country-level basic reproductive ratios for novel coronavirus (COVID-19) using synthetic contact matrices, 2020. Available: https://www.medrxiv.org/content/10.1101/ 2020.02.26.20028167v1.full.pdf

61 Rhodes T, Lancaster K. Mathematical models as public troubles in COVID-19 infection control: following the numbers. Health Sociology Review 2020;368:1-18.

62 Rhodes T, Lancaster K, Rosengarten M. A model Society: maths, models and expertise in viral outbreaks. Crit Public Health 2020;30:253-6.

63 Montgomery C, Engleman L. Epidemiological publics? On the domestication of models in the era of COVID 19, Somotasphere, 2020. Available: http://somatosphere.net/2020/epidemiological-publics-onthe-domestication-of-modelling-in-the-era-of-covid-19.html/

64 Douglas M, Katikireddi SV, Taulbut M, et al. Mitigating the wider health effects of covid-19 pandemic response. BMJ 2020;369:m1557.

65 Funk S, Bansal S, Bauch CT, et al. Nine challenges in incorporating the dynamics of behaviour in infectious diseases models. Epidemics 2015;10:21-5.

66 Latour B. Why has critique run out of steam? From matters of fact to matters of concern. Crit Inq 2004;30:225-48.

67 Van Egmond S, Zeiss R. Modelling for policy: science-based models as performative boundary objects for Dutch policy making. Sci Stud 2010;23:58-78.

68 Scoones I, Jones K, Lo lacono G, et al. Integrative modelling for one health: pattern, process and participation. Philos Trans $R$ Soc Lond B Biol Sci 2017;372:20160164. 